\title{
China Village Stage: Architecture and Decoration Arts on LEPING Ancient Opera Stage
}

\author{
Ling YANG ${ }^{1, a}$, Mingchun ZHANG ${ }^{2, b,{ }^{*}}$ \\ 1 Department of Environmental Design, Arts \& Design College of Jingdezhen Ceramic Institute, \\ Jingdezhen City, China, 333001 \\ 2 Department of Product Design, Arts \& Design College of Jingdezhen Ceramic Institute, \\ Jingdezhen City, China, 333001 \\ a59342252@qq.com, b364689176@qq.com \\ ${ }^{*}$ Corresponding author
}

Keywords: Leping ancient opera stage; Ancestral hall stage; Perpetual stage; Opera carving.

\begin{abstract}
There is a traditional type of architecture in Leping County, China, which is China village opera stage. It is usually used for Gan opera performance and as a center space for villagers' social communication. There are two main types of stage: ancestral hall stage and perpetual stage. Layout of opera stage is arranged tightly with Gan opera audience, which is fully utilized stage space for interaction and chorus. Opera carving decorations are all well portrayed Gan opera figures and story scenes, which play an important role in moral and ethnic education.
\end{abstract}

\section{Introduction}

Leping is a county located in the northeast of Jiangxi Province, China. It lies on 28.98 degrees north latitude and 117.15 degrees east longitude, 60 kilometers east of Poyang Lake. Leping is famous for China village opera stages, which has a reputation as a live "Ancient Chinese Stage Museum". Stage is a center of social culture life, which is integrated cultural space with Chinese opera, architecture, history, folk custom, religion and so on. China village stage has hundreds of years' history as Chinese traditional architecture type. Many existing ancient opera village stages are well protected as tangible cultural heritage in Leping County ${ }^{[1]}$.

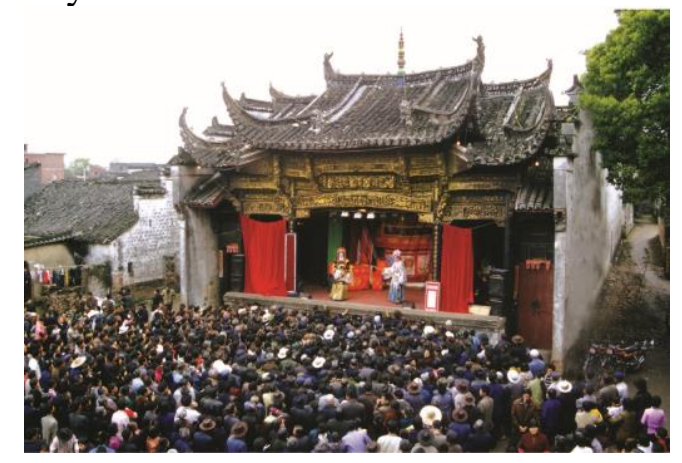

Fig.1. Shine stage of ancestral hall stage in Huyan village.

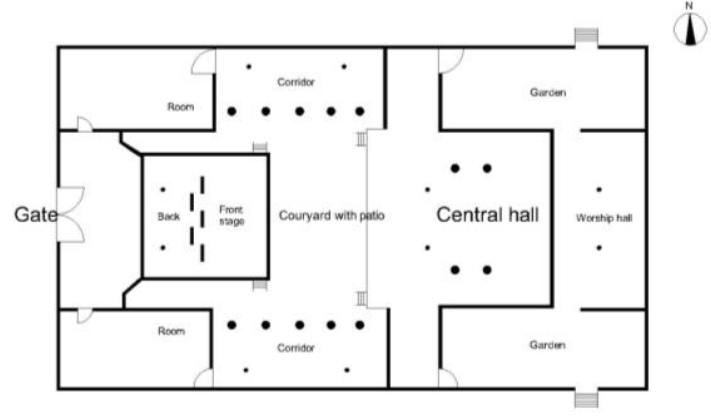

Fig.2. General sketch of Dunben hall in Chexi village. 


\section{Architecture Types of Leping Ancient Opera Stage}

Ancient stage is mainly used for Gan Opera (a type of Chinese opera) performance in Leping County. Most existing stages are ancestral hall stage and perpetual stage ${ }^{[2]}$. According to performance forms of Gan Opera, there are two ancestral hall stage types which are single side performance stage named shine stage and double sides stage named rain and shine stages. For double sides stage (Fig.1), the shine stage is always facing a spacious plaza for villagers watching opera in an open field. The rain stage is just back of shine stage and facing to an open yard with patio in ancestral hall for clansmen sitting in to watch opera just like a private theater. Perpetual stage is similar to shine stage but absolutely single architecture with no ancestral hall behind and it always lies in the center of whole village with more spacious ground.

2.1 Typical Stage Types. Ancestral hall stage is the earliest typical stage architecture in Leping County ${ }^{[3]}$. It is absolutely closed loop courtyard with an open patio and two corridors (sometimes corridors with floors) in the central area. The stage is just opposite to an ancestral hall. Take Chexi village stage (also named Dunben hall) as an example (Fig.2), the ancestral hall stage lies west part of the village behind a half-moon shaped pool. The ancestral hall lies east and faces west, covering an area of 30 meters wide and 60 meters long, about 2,000 square meters. The ancestral hall architecture was built south north symmetry and it has front gate, ancestral hall stage, courtyard with patio, central hall, worship hall in that order in the central axis. There are floor corridors, kitchen and garden along both northern and southern sides in the ancestral hall. The biggest courtyard with patio lies in the center of the building. There are ancestral hall stage lying to the west, central hall lying to the east, floor corridors lying to the north and south. Wood screens are built on the stage which is separated by front stage as performance area and back stage as waiting space. Front stage covers 10.9 meters wide and the main area is nearly a square with 6.35 meters wide and 6.1 meters deep. The stage is 1.5 meters height. Back stage lies just back of wood screen but it is a little smaller. It covers the same 10.9 meters wide, 4.1 meters wide and 2.9 meters deep. When family members get together and make a ceremony for worship, they usually invite opera actors to make several days' performance. At that time, villagers are crowded everywhere, standing in the courtyard, central hall and both sides of the corridors.

Perpetual stage is a single architecture type which is different in building scale, spatial relationship and structure. From the stage scale aspect view, they are totally different stages. There are different types perpetual stages: they are three spaces and straight roof supported by four pillars, three spaces and one roof supported by four pillars, three spaces and three rooves supported by four pillars, five spaces and five rooves supported by four pillars and other different intricate stages type. But from the layout plan, fundamental structures, architecture appearance and other aspects view, perpetual stage is the same as other different types of stage. Perpetual stage is usually situated in the central of village, which is an important identification landscape with a big open yard for more people to attend an opera ${ }^{[4]}$. It is also a public social center for villagers to communicate and get information. The most famous perpetual stage built in Ming and Qing Dynasty is the perpetual stage in Southern Jieshou village (Fig.3).

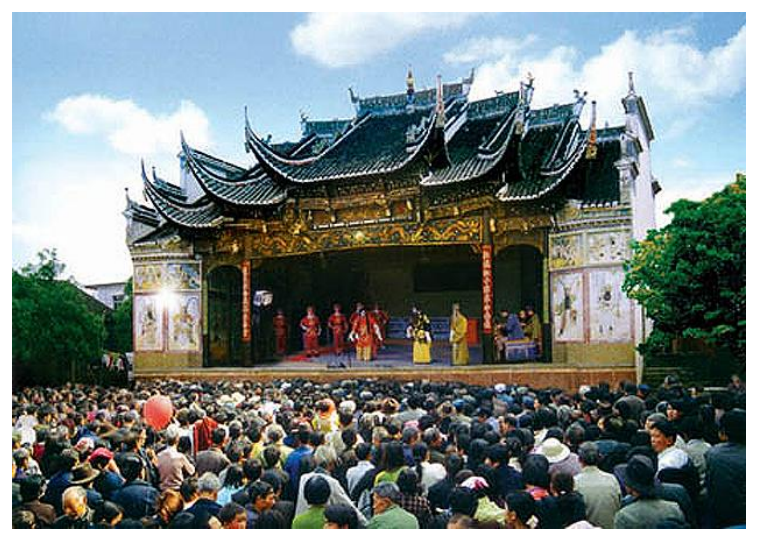

Fig.3. Perpetual stage in Southern Jieshou village. 


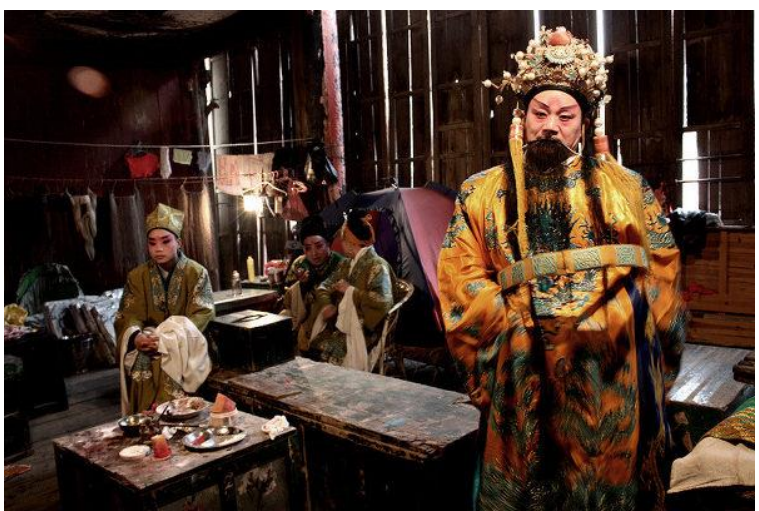

Fig.4. Waiting space on the back stage.

Perpetual stage is a new type of stage based on ancestral hall stage, but absolutely isolated from ancestral hall. It is a single architecture and enhances public space for more villagers to attend an opera performance ${ }^{[5]}$. It is just like a new open theater for all villagers.

Besides ancestral hall stage and perpetual stage, there are another existing stage types such as guild hall stage, temple stage and family stage now in Leping County.

2.2 Stage Structure. Leping village stages usually have three spaces with four wooden pillars or five spaces with four wooden pillars which are usually decorated by Golden Toad. Stage is divided by wooden screen wall into front and back stage. Front stage is used for performance which is about 20 70 square meters and back stage is used for waiting. Back stage is a little smaller and occasionally used as a storage space for box props or for actors dressing and face painting. There are doors with characters "Chujiang" and "Ruxiang" on the screen wall ${ }^{[6]}$. Chujiang is on the left side for actors" leaving from the stage. Ruxiang is on the right side for actors' stepping on the stage. Some village stage has six more doors for performance transition. It is an excited scene for villagers to see more actors moving together.

Traditional Gan opera performance has less sceneries but screen walls are usually decorated by complicate sculptures, paintings, golden wood carvings which are made as a main background. Sometimes, desks and chairs are used as props on front stage. They are used as a partition for dividing front stage into main space for actors and subordinate space for opera band. Back stage is built with simple decoration but it is still a part of performance stage. (Fig.4)

\section{Carving Decoration on Ancient Stage}

Stage carving is the most extinguished architecture characteristics during all stage decoration arts ${ }^{[7]}$. These decorations are carved on top beams, pillars, cornices, screen wooden walls and window frames, which are nearly all over the stage. Contents of the decoration are usually mountains and rivers, flowers and birds, celestial beings and auspicious beasts, pavilions and pagodas, opera figures and opera scenes. Decoration related with opera scene is named opera carving which is one of the extinguished features of stage decoration in Leping County.

3.1 Handcraft Features of Opera Carving. Handcraft of opera carving features are mainly on relief sculpture, flat carving and negative carving techniques. They are seldom twice polished, only once carved where it shows clear carving knife marks: simple, natural, sharp and hard. There are as many as a hundred more kinds of carving tools which handicraftsmen made by their hands. These carving tools together with handcrafts of opera carving are transferred from generation to generation ${ }^{[8]}$. (Fig.5) 


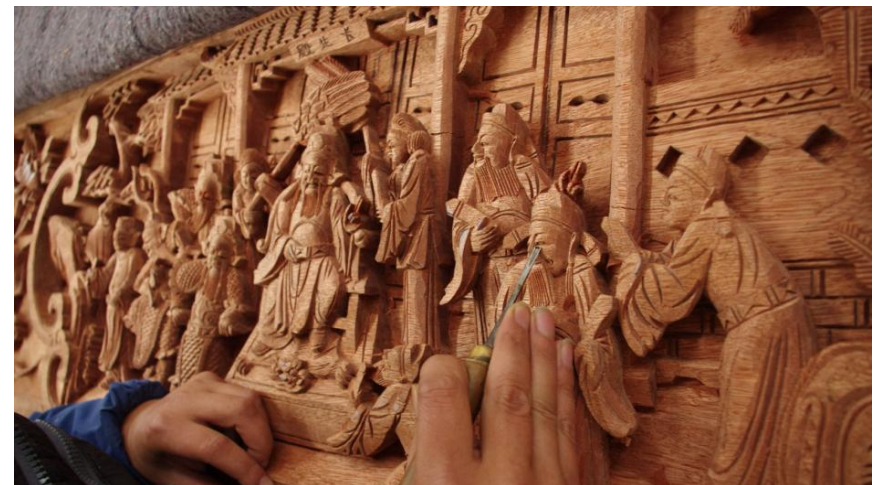

Fig.5. Handicraftsman is making figures for opera carving in traditional ways.

Opera carvings made on ancient stage are mainly on wood. Some others are brick carvings. Opera carvings are always colored by authentic gold foil on some exquisite stages and typed colored. Typed colored is the way to express opera story and figures' different features. Different colors are used for increasing festival atmosphere. Typed colored technique balances the dull color of the stage and it is always used for external opera carving decorations. Gold foil decoration is used as upper layer on red lacquered bottom. It is used for interior opera carving decorations. The reasons are that gold foil is bright enough for dark space of stage. Moreover, it makes the stage gorgeous and magnificent.

3.2 Subjects of Opera Carving. There are three common subjects of opera carving which are family ethic, typical story and worships. Family ethic and best wishes expressed family harmony are the most common subjects which are usually carved in the central area of top beam. They are always built the most important and prominent place. There are usually carved characters "Man Tang Fu" which means best wishes along with the whole family, "Nine generations living together" which means nine relative families are living a happy life and the same as "Five generations living together". They are all showing a big family with respect for elders who are carved higher central place and surrounded by their children. They all have a big smile on their faces which express a harmonious scene of the big family. ${ }^{[9]}$

3.3 Carving Content: Competition of Kungfu Skills for Elders' Entertainment. Opera carving contents focus on Kungfu competition scenes. Take Xiaxu village stage's opera carving as an example, the "Nine generations living together" carving shows a harmonious atmosphere of a big family. Two younger children make firm a horse stance. Under the elder's gaze with love affection, children are making Kungfu competition as entertainment for the whole family. Kungfu competition is emphasized by Gan opera for attraction and also it is related with social customs for Kungfu adoration. Gan opera is famous for full-length scenes and history stories which show expression of simple, rough and bold. These performance actions strongly shock the audience, which all reflect villagers' Kungfu adoration tradition. These are all recorded by opera carving decorations on stage.

\section{Summary}

Four hundreds of years ago, villagers built their own village stage for opera performance. They built ancestral hall stage, perpetual stage and different other types of stage architecture. Opera carvings have distinguished art features together with China ancient stage. They are all well protected and inherited from generation to generation. And now, villagers today in Leping County still keep the life style of attending opera performance. These are clues to help us read China rural society, rural culture and aesthetics. These are a kind of relic archive materials for deep research.

\section{References}

[1] Chinese opera history edition committee, Beijing: China ISBN express center: Jiangxi Collection, Records of Chinese Opera, pp. 13- 15, 1998.

[2] Yibai ZHOU, Shanghai: shanghai book store express: Chinese Opera History, pp. 154-155, 2004. 
[3] Linping XUE, Beijing: Chinese architecture industrial express: China Traditional Opera Architecture, pp. 70-76, 2009.

[4] Wenming CHE, Beijing: cultural art express: Discovery of Opera Relic and Opera Research in the 20th Century, pp. 297-305, 2001.

[5] Huifu HUANG, Gan opera and LEPING ancient opera stage, Journal of national academy of Chinese theater arts, vol. 18, pp. 95-96, 1997.

[6] Binghuang WU, Jiangxi Normal University: The Research on Ancient Stages of LEPING, 2006.

[7] Bin QIU, Wei ZHANG, art characteristics of LEPING ancient opera stage, Southeast Culture, vol. 17, pp. 74-77, 2003.

[8] Wenming CHE, general investigation summary of LEPING ancient stage, Cultural Relics in Southern China, vol. 47, pp. 177-186, 2009.

[9] Wangnan ZHANG, Huizhou ancient stages and their architecture characteristics, China Homes, vol. 1, pp. 48-53, 2008. 